\title{
Five-year clinical outcomes of Crohn's disease: a report of 287 multiethnic cases from an International Hospital in Thailand
}

This article was published in the following Dove Press journal: Clinical and Experimental Gastroenterology

\section{Vibhakorn Permpoon' Krit Pongpirul ${ }^{2-4}$ Sinn Anuras' \\ 'Digestive Disease Center, Bumrungrad International Hospital, Bangkok, Thailand; ${ }^{2}$ Department of Preventive and Social Medicine, Faculty of Medicine, Chulalongkorn University, Bangkok, Thailand; ${ }^{3}$ Department of International Health, Johns Hopkins Bloomberg School of Public Health, Baltimore, MD, USA; ${ }^{4}$ Bumrungrad Research Center, Bumrungrad International Hospital, Bangkok, Thailand}

\section{Video abstract}

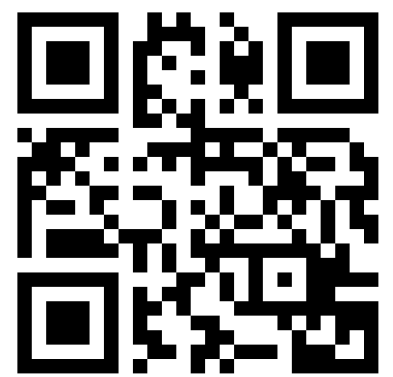

Point your SmartPhone at the code above. If you have QR code reader the video abstract will appear. Or use: https://youtu.be/-xvSTN P q0
Correspondence: Krit Pongpirul Department of Preventive and Social Medicine, Faculty of Medicine, Chulalongkorn University, I873 Rama IV Rd., Pathumwan, Bangkok 10330, Thailand Tel +6 6866055088

Email doctorkrit@gmail.com
Background: Crohn's disease (CD) has been relatively rare in Asian region whereas its clinical outcomes have been dominated by evidence from Caucasians in developed countries. This study reported clinical characteristics and outcomes of the multiethnic patients who visited our institution.

Materials and methods: Medical records of all patients who visited our institution during 2005-2010 were reviewed. Colonoscopy and sigmoidoscopy were performed in compliance with the ASGE guidelines.

Results: A total of $287 \mathrm{CD}$ patients were followed up for 5.65 years on average: $41.80 \%$ Middle Eastern (ME), 29.62\% Caucasian, 28.57\% Asian. ME and Caucasian had higher CD prevalence than Asian $(286.71,278.66$, and 43.10 per 100,000 population, respectively). Significant variation in male proportion was observed $(p=0.001): 39.02 \%$ Asian, $65.83 \%$ ME, 68.24\% Caucasian. The mean age was 39.46 years (ME 32.88, Asian 43.35, Caucasian $45.00 ; p<0.001)$. ME had alonger duration of symptoms (26.55 months) than Caucasian (11.98 months) and Asian (12.35 months) ( $p=0.0008)$. The proportions of perianal lesions were statistically different across ethnic origins $(p=0.014): 9.76 \%$ Asian, $24.17 \% \mathrm{ME}$ and $12.94 \%$ Caucasian. Caucasian was severely active, compared with ME (10.83\%) and Asian $(6.10 \%)$. Disease progression existed in 88 of 254 patients who initially had non-severe pathology: 19.63\% ME, 40\% Caucasian, 50.65\% Asian $(p<0.0001)$. Clinical improvement was observed in $82 \%$ of the patients. Seventy-five patients required either surgery or hospitalization with a significant ethnic variation: $37.65 \%$ Caucasian, $28.33 \% \mathrm{ME}, 10.98 \%$ Asian $(p<0.0001)$.

Conclusions: Crohn's disease prevalence, gender, age, duration of symptoms, perianal lesion, pathological severity and disease progression varied across ethnic origins.

Keywords: Crohn's Disease, ethnic groups, anatomical pathological conditions, medical tourism, retrospective studies

\section{Introduction}

Crohn's disease (CD) has been geographically varied and relatively rare in Asian region whereas North American and European Caucasians had a higher incidence and prevalence than the rest of the world. ${ }^{1}$ The incidence rate of $\mathrm{CD}$ varied across countries in Asia, ranging from 0.07 to 3.12 per 100,000 people, ${ }^{2-7}$ compared with the worldwide incidence of $C D$ that varied from 0.1 to 16 per 100,000 population.${ }^{8,9}$ While the prevalence of CD could be as high as 18.6 per 100,000 population in Hong Kong, ${ }^{7}$ it is still significantly less than Western countries. 
Despite the epidemiological information presented above, clinical outcomes of $\mathrm{CD}$ have been dominated by evidence from the Caucasian population in developed countries. Ten-year survival rates varied from 90\% (Italy), ${ }^{10} 91 \%$ (Denmark), ${ }^{11} 95 \%$ (United Kingdom), ${ }^{12}$ $96 \%$ (Sweden) ${ }^{13}$ to $99 \%$ Australia. ${ }^{14}$ Before the introduction of infliximab, two large Swedish cohorts reported $96 \% 10$-year ${ }^{13}$ and $94 \% 15$-year ${ }^{15}$ survival rates, respectively. Longer-term survival data at 30 years of $93 \%$ and $73 \%$ were based on Australia ${ }^{14}$ and the US studies. ${ }^{16}$ The survival rates reported by these countries might reflect not only varying genotype characteristics, clinical response of the patients, but also the health care services provided to them.

Attempt to include non-Caucasian subjects in developed countries had not been able to gain a sufficient number of sample for statistical inference and therefore was excluded from the analysis of clinical outcomes. ${ }^{12}$ To date, three major Asian studies have been conducted. In the Asia-Pacific Crohn's and Colitis Epidemiology Study (ACCESS), 166 new CD patients in 8 countries were reported (incidence 0.54 per 100,000 population). ${ }^{6}$ In alarge population-based epidemiological study conducted in Hong Kong, an accumulated 983 CD cases were assessed but no clinical outcomes were reported. ${ }^{7}$ To date, the largest non-Caucasian clinical data of IBD is the ACCESS cohort, but less than $200 \mathrm{CD}$ cases were included in its early phase. ${ }^{17}$

This study was aimed to report clinical characteristics including disease severity and complication at presentation and outcomes of 287 domestic and international patients who visited our institution.

\section{Materials and methods}

We reviewed demographics, clinical characteristics, investigation results and clinical outcomes in medical records of all patients who visited Bumrungrad International Digestive Disease Center (BIDDC) during 2005-2010. Colonoscopy and sigmoidoscopy were performed in compliance with the American Society for Gastrointestinal Endoscopy (ASGE) practice guidelines.

Patient ethnicities were arbitrarily categorized into 3 groups: Asian (Thai, Oriental Non-Thai, South Asian), Middle Eastern and Caucasian. Disease severity was classified based on pathological findings into inactive, mild, moderate and severe using the modified Riley Histopathological Activity Score. The need for surgical consultation was based on the content of relevant operative note in the medical record. The follow-up period was estimated from the date of $\mathrm{CD}$ diagnosis and date of last follow-up visit.

Descriptive statistics were used where appropriate. Association between categorical variables was analyzed using chi-square test or Fischer's exact test. Association between categorical and interval variables was analyzed using Student's $t$-test and/or analysis of covariance (ANOVA) where appropriate.

\section{Ethical considerations}

This study was approved by Bumrungrad International Institutional Review Board (BI/IRB No.146-09-11). This study was performed in compliance with the Declaration of Helsinki, the CIOMS International Guidelines for Ethical Review of Epidemiological Studies, as well as applicable Thai laws. The patient consent to review their medical records was not required because the written informed consent was very unlikely obtainable in this retrospective study and that re-contacting these patients to obtain consent may lead to privacy breach. Patient data were stored electronically within our secured hospital information system. The data could be accessed only by authorized health professionals using their own staff codes. Patient's name and identification number were omitted and rendered anonymous before data analysis.

\section{Results}

As many as 262,606 individuals visited BIDDC during 2005-2010. The distribution of patients' ethnicity visiting the BIDDC was slightly different from hospital patient ethnic profiles (Thai:Non-Thai $=60: 40$ ).

A total of $287 \mathrm{CD}$ patients were followed up for 5.65 years on average (95\% CI: 4.92 to 6.39). Forty-twopercent were Middle Eastern (41.80\%), followed by Caucasian (29.62\%) and Asian (28.57\%). Data presented in Table 1 suggested that Middle Eastern and Caucasian had significantly higher prevalence of $\mathrm{CD}$ than that of Asian patients (286.71 and 278.66, respectively, vs 43.10 per 100,000 population).

While most of the cases were male (58.89\%), there was significant variation in gender distribution $(p=0.001)$ : Asian male $39.02 \%$, compared with $65.83 \%$ Middle Eastern and $68.24 \%$ Caucasian male. The overall mean age was 39.46 years with significant variation across ethnic origins $(p<0.001)$, ranging from 32.88 (Middle East) to 43.35 (Asian) and 45.00 (Caucasian) years. Only $8.74 \%$ of the cases reported that they smoked at least 100 cigarettes in life. 
Table I Ethnicity distribution of Crohn's disease and total gastrointestinal patients (2005-2010)

\begin{tabular}{|l|l|l|l|l|l|l|l|l|l|}
\hline Ethnicity & $\mathbf{2 0 0 5}$ & $\mathbf{2 0 0 6}$ & $\mathbf{2 0 0 7}$ & $\mathbf{2 0 0 8}$ & $\mathbf{2 0 0 9}$ & $\mathbf{2 0 1 0}$ & Total & Crohn & $\begin{array}{l}\text { Institution-Specific Prevalence (per } \\
\text { 100,000) }\end{array}$ \\
\hline $\begin{array}{l}\text { Asian } \\
\text { Middle }\end{array}$ & 26,482 & 29,036 & 29,319 & 34,004 & 35,404 & 36,005 & 190,250 & 82 & 43.10 \\
$\begin{array}{l}\text { Eastern } \\
\text { Caucasian }\end{array}$ & 4,088 & 6,418 & 7,828 & 7,726 & 9,483 & 41,853 & 120 & 286.71 \\
Total & 35,137 & 39,579 & 41,001 & 47,041 & 48,788 & 51,060 & 262,606 & 287 & 109.29 \\
\hline
\end{tabular}

Sixty-seven percent of the patients presented with no more than oneyear of symptoms. Patients experienced CD symptoms for amean of 18.41 months (95\% CI 13.62-23.20) before seeking for medical attention. Middle Eastern patients were more likely to have symptoms for more than two years (26.55 months), as compared to Caucasian (11.98 months) and Asian patients ( 12.35 months) $(p=0.0008)$.

One-third of the patients $(32.00 \%)$ had only perianal lesions whereas $28.67 \%, 20.00 \%, 19.33 \%$ had ileitis, ileocolitis and colitis, respectively. Only $9.76 \%$ of Asian patients had perianal lesions, compared with $24.17 \%$ and $12.94 \%$ of Middle Eastern and Caucasian patients, respectively. The proportions of perianal lesions were statistically different across ethnic origins $(p=0.014)$.

Half of the patients $(49.48 \%)$ had mildly active CD whereas $11.50 \%$ were severely active. Fifteen out of 85 (17.65\%) Caucasian patients were severely active, compared with Middle Eastern (10.83\%), and Asian (6.10\%). Penetrative CD was identified in 7 patients (1 enterovesical, 2 entero-enteral, 3 intra-abdominal, 1perineal fistula, 2 recto-vaginal and 3 entero-cutaneous fistula).

As immunosuppressive drug and biologic agent were used in only $14.98 \%$ and $5.92 \%$, respectively, the need for steroid was used to determine disease exacerbation. Of 254 non-severe cases $(88.50 \%), 34.65$ eventually received steroids during the study period, suggesting that disease progression existed among one-third of the patients who initially had non-severe pathology. The disease progression significantly varied across ethnic groups, from $19.63 \%$ of Middle Eastern cases, to $40.00 \%$ and $50.65 \%$ of Caucasian and Asian patients, respectively $(p<0.0001)$.

Clinical improvement was observed in $82.16 \%$ of the patients. However, 75 patients required surgery and hospitalization with significant ethnic variation $337.65 \%$ of Caucasian, $28.33 \%$ of Middle Eastern and $10.98 \%$ of Asian; $p<0.0001)$.

Extra-intestinal manifestations were found in 18 cases (6.27\%): 1 erythema nodosum, 2 psoriasis, 1 arthritis, 4 non-specific arthralgia, 4 oropharyngeal ulcer, 5 osteoporosis or osteomalacia, 1 primary sclerosing cholangitis. Penetrating disease was found in 7 cases (2.52\%): 4 Middle Eastern, 2 Caucasian and 1 Asian. Fourteen patients had single lesion: 1 entero-vesical, 2 entero-enteral, 3 intraabdominal, 1perineal, 2 recto-vaginal, 3 entero-cutaneous fistula. One Middle Eastern patient had six fistula lesions. Colon cancer was developed in one Asian and one Caucasian patients who were severely and moderately active, respectively.

\section{Discussion}

Given relatively equal proportions of Caucasian, Asian and Middle Eastern patients with CD in a single institution, findings from our study added comparative analysis of clinical characteristics and outcomes across major ethnic origins. Some important factors including ethnicity, age and gender should also be considered as part of the CD activity discussed below.

The CD prevalence of Middle Eastern and Caucasian patients was six times more than that of Asian patients. Although the institution-specific prevalence was relatively much higher than that of population-based studies and could not be generalizable to the population, the findings were comparatively proportional to previous Middle Eastern and Asian studies. The prevalence of CD ranged from 53.1 to 65.1 per 100,000 Middle Eastern population, ${ }^{18-20}$ compared with 1.3 to 18.6 per 100,000 in Hong Kong, ${ }^{7,21} 5.8$ to 13.5 per 100,000 Japanese, ${ }^{2,3} 11.2$ per 100,000 Korean $^{5}$ and 7.2 per 100,000 Singaporean population. Nonetheless, the significant variation of $\mathrm{CD}$ prevalence in the Caucasian population from 40 to 54 per 100,000 in Europe, ${ }^{22,23} 162-201$ per 100,000 in North America, ${ }^{24,25} 214$ per 100,000 in the United Kingdom ${ }^{26}$ made it difficult to compare with that of the Asian population. While the ACCESS study reported that CD was more common in Asia than Australia, ${ }^{17}$ this study added evidence from Middle Eastern and non-Australian Caucasian.

Our data suggested that age and gender effects on the disease prevalence might be different across ethnic origins. 
In contrast to the finding from Hong Kong registry, CD was not male predominant among our Asian patients (male:female ratio $=0.64$ vs 1.86$){ }^{7}$ As a comparable number of male and female patients visited our hospital, gender could not account for the differential prevalence of $\mathrm{CD}$ between male and female. The age difference across patient ethnic groups might reflect differential accessibility to health services at a facility for medical tourism. At our institution, Middle Eastern patients were more likely to get medical expenses covered by their government and, therefore, much less financial barriers to the diagnosis and treatment of their health problems. The majority of them expressed relatively higher trust in our medical facility than that in their own countries. On the contrary, most Caucasian patients were expatriates who usually have health insurance from their countries that covered medical expense abroad upon request.

Our patients from any ethnic origin had three times longer duration of symptoms before final diagnosis of CD than the previously reported median time of 5.5 months in ACCESS study. ${ }^{6}$ It is possible that local doctors had already managed patients with short duration of symptom whereas those with longer duration had to seek medical care abroad. Further study is required to test this hypothesis. Interestingly, Middle Eastern patients had more than two years of symptoms before seeking medical care. Although anecdotal data from an informal interview with the patients suggested how much they trust their own health care system, more evidence is needed to get a better understanding of this phenomenon.

Overlapping terms/concepts of severity have been used in existing literature with inconclusive definitions. In our study, pathological severity (inactive, mild, moderate and severe $)^{27}$ was used as a baseline reference for clinical improvement assessment in the subsequent visits. In other studies, anatomical aspect was used as aseverity criteria, so having perianal lesion was considered worse disease behavior. ${ }^{17} \mathrm{~A}$ relatively large proportion of isolated perianal CD lesions, along with the significantly different prevalence of isolated perianal lesions across ethnic origins, suggested that perianal $\mathrm{CD}$ could be regarded as a "type" rather than a "complication" of CD. The perianal lesion should, therefore, be categorized as disease location (L5), not disease behavior presented in some large study like ACCESS. ${ }^{17}$

Findings from our study suggested that some demographic variables, especially ethnicity, age and gender, could be useful and simple enough for disease severity determination. Existing clinical scores for CD such as Crohn's Disease Activity Index (CDAI) has been introduced in $1976^{28}$ with no major modification since then. CDAI comprised 8 (4 symptom-related, 1 sign-related, 1 laboratory, 1 physiological and 1 medication-related) items. Likewise, the Harvey-Bradshaw Index Score comprised 5 simplified items selected from the CDAI. ${ }^{29}$ Both scores did not take ethnicity and age into account whereas gender was only indirectly incorporated into the CDAI formula as a reference for hematocrit determination. Further study to compare the scores across these variables should be conducted.

The need for immunosuppressive drugs including steroids, azathioprine and other biologic agents as well as the need for surgery have been used to reflect disease severity. However, in some settings like ours, these medications have not been common; pathological findings are therefore crucial for the determination of disease severity. Instead, the need for these medications was used to determine disease progression in our patients. The variation of disease progression across patients from various ethnic origins should be considered at the initial discussion with apatient. For example, Asian patients are less likely to have severe $\mathrm{CD}$ at presentation than Caucasian patients but they are more likely to get immunosuppressive drugs or biologic agents but less likely to be operated.

As a tertiary-level hospital for medical tourism that provides care to arelatively wealthy group of domestic and international patients, some findings from this study, especially the clinical outcomes, might not be generalized to the population.

\section{Conclusions}

Crohn's disease prevalence, gender, age, duration of symptoms, perianal lesion, pathological severity and disease progression varied across ethnic origins.

\section{Acknowledgments}

The authors would like to thank the Knowledge Angels of Bumrungrad Research Center for their kind help with data collection and analysis. The abstract of this paper was presented at the Asian Pacific Digestive Week (APDW) conference, September 23-26, 2017, in Hong Kong as a poster presentation with interim findings. The poster's abstract was published in Journal of Gastroenterology and Hepatology 2017: https://onlinelibrary.wiley.com/doi/pdf/ 10.1111/jgh.13877. No specific funding has been received. The data have been generated as part of the routine clinical care of the hospital. 


\section{Disclosure}

The authors report no conflicts of interest in this work.

\section{References}

1. Loftus EV Jr. Clinical epidemiology of inflammatory bowel disease: incidence, prevalence, and environmental influences. Gastroenterology. 2004;126(6):1504-1517.

2. Morita N, Toki S, Hirohashi T, et al. Incidence and prevalence of inflammatory bowel disease in Japan: nationwide epidemiological survey during theyear 1991. JGastroenterol. 1995;30(Suppl 8):1-4.

3. Yao T, Matsui T, Hiwatashi N. Crohn's disease in Japan: diagnostic criteria and epidemiology. Dis Colon Rectum. 2000;43(10 Suppl): S85-S93. doi:10.1007/BF02237231

4. Leong RW, Lau JY, SungJJ. The epidemiology and phenotype of Crohn's disease in the Chinese population. Inflamm Bowel Dis. 2004;10(5):646-651.

5. Yang SK, Yun S, Kim JH, et al. Epidemiology of inflammatory bowel disease in the Songpa-Kangdong district, Seoul, Korea, 1986-2005: aKASID study. Inflamm Bowel Dis. 2008;14(4):542-549. doi:10.1002/ibd.20310

6. Ng S C, Tang W, Ching JY, et al. Incidence and phenotype of inflammatory bowel disease based on results from the Asia-pacific Crohn's and colitis epidemiology study. Gastroenterology. 2013;145 (1):158-165 e152. doi:10.1053/j.gastro.2013.04.007

7. NgSC, LeungWK, ShiHY, etal. Epidemiology of inflammatory bowel disease from 1981 to 2014: results from a territory-wide populationbased registry in Hong Kong. Inflamm Bowel Dis. 2016;22(8):1954 1960

8. Molodecky NA, Soon IS, Rabi DM, et al. Increasing incidence and prevalence of the inflammatory bowel diseases with time, based on systematic review. Gastroenterology. 2012;142(1):46-54e42. quiz e30.

9. Cosnes J, Gower-RousseauC, Seksik P, Cortot A. Epidemiology and natural history of inflammatory bowel diseases. Gastroenterology. 2011;140(6):1785-1794.

10. Palli D, Trallori G, Saieva C, et al. General and cancer specific mortality of apopulation based cohort of patients with inflammatory bowel disease: the Florence Study. Gut. 1998;42(2):175-179.

11. Jess T, Winther KV, Munkholm P, Langholz E, Binder V. Mortality and causes of death in Crohn's disease: follow-up of apopulationbased cohort in Copenhagen County, Denmark. Gastroenterology. 2002;122(7):1808-1814.

12. Probert CS, Jayanthi V, Wicks AC, Mayberry JF. Mortality from Crohn's disease in Leicestershire, 1972-1989: an epidemiological community based study. Gut. 1992;33(9):1226-1228.

13. Ekbom A, Helmick CG, Zack M, Holmberg L, Adami HO. Survival and causes of death in patients with inflammatory bowel disease: a population-based study. Gastroenterology. 1992;103(3):954-960.
14. Selinger CP, Andrews J, Dent OF, et al. Cause-specific mortality and 30-year relative survival of Crohn's disease and ulcerative colitis. Inflamm Bowel Dis. 2013;19(9):1880-1888. doi:10.1097/ MIB.0b013e31829080a8

15. Persson PG, Bernell O, Leijonmarck CE, Farahmand BY, HellersG, AhlbomA. Survival and cause-specific mortality in inflammatory bowel disease: a population-based cohort study. Gastroenterology. 1996;110(5):1339-1345.

16. Loftus EV Jr., SilversteinMD, Sandborn WJ, Tremaine WJ, Harmsen WS, Zinsmeister AR. Crohn's disease in Olmsted County, Minnesota, 1940-1993: incidence, prevalence, and survival. Gastroenterology. 1998;114(6):1161-1168.

17. Ng SC, Zeng Z, Niewiadomski O, et al. Early course of inflammatory bowel disease in a population-based inception cohort study from 8 countries in Asia and Australia. Gastroenterology. 2016;150(1):8695e83; quiz e13-84. doi:10.1053/j.gastro.2015.09.005

18. Yang SK, Loftus EV Jr., Sandborn WJ. Epidemiology of inflammatory bowel disease in Asia. Inflamm Bowel Dis. 2001;7(3):260-270.

19. Shapira M, Tamir A. Crohn's disease in the Kinneret sub-district, Israel, 1960-1990. Incidence and prevalence in different ethnic subgroups. Eur JEpidemiol. 1994;10(2):231-233.

20. Abdul-Baki H, ElHajj I, El-Zahabi LM, et al. Clinical epidemiology of inflammatory bowel disease in Lebanon. Inflamm Bowel Dis. 2007;13(4):475-480. doi:10.1002/ibd.20022

21. Sung JJ, Hsu RK, Chan FK, Liew CT, Lau JW, Li AK. Crohn's disease in the Chinese population. An experience from HongKong. Dis Colon Rectum. 1994;37(12):1307-1309.

22. Trallori G, Palli D, Saieva C, et al. A population-based study of inflammatory bowel disease in Florence over 15 years (1978-92). Scand JGastroenterol. 1996;31(9):892-899.

23. Langholz E, Munkholm P, Nielsen OH, KreinerS, Binder V. Incidence and prevalence of ulcerative colitis in Copenhagen county from 1962 to 1987. Scand JGastroenterol. 1991;26(12):1247-1256.

24. Loftus CG, Loftus EV Jr., Sandborn WJ, et al. Update on incidence and prevalence of Crohn's disease (CD) and ulcerative colitis (UC) in Olmsted county, Minnesota. Gastroenterology. 2003;124(4):A36. doi:10.1016/S0016-5085(03)80177-4

25. Kappelman MD, Rifas-Shiman SL, Kleinman K, et al. The prevalence and geographic distribution of Crohn's disease and ulcerative colitis in the United States. Clin Gastroenterol Hepatol. 2007;5 (12):1424-1429.

26. Montgomery SM, Morris DL, Thompson NP, Subhani J, Pounder RE, Wakefield AJ. Prevalence of inflammatory bowel disease in British 26year olds: national longitudinal birth cohort. BMJ. 1998;316 (7137):1058-1059.

27. Geboes K, Dalle I. Influence of treatment on morphological features of mucosal inflammation. Gut. 2002;50(Suppl 3):III37-III42.

28. Best WR, Becktel JM, Singleton JW, Kern F Jr. Development of aCrohn's disease activity index. National Cooperative Crohn's Disease Study. Gastroenterology. 1976;70(3):439-444.

29. Harvey RF, Bradshaw JM. Asimple index of Crohn's-disease activity. Lancet. 1980;1(8167):514. doi:10.1016/S0140-6736(80)92767-1 


\section{Publish your work in this journal}

Clinical and Experimental Gastroenterology is an international, peerreviewed, open access, online journal publishing original research, reports, editorials, reviews and commentaries on all aspects of gastroenterology in the clinic and laboratory. This journal is indexed on American Chemical Society's Chemical Abstracts Service (CAS).
The manuscript management system is completely online and includes a very quick and fair peer-review system, which is all easy to use. Visit http://www.dovepress.com/testimonials.php to read real quotes from published authors. 